This is a PDF file of an unedited manuscript that has been accepted for publication in Public Health. The manuscript will undergo copyediting, typesetting, and review of the resulting proof before it is published in its final form. Please note that during the production process errors may be discovered which could affect the content, and all legal disclaimers that apply to the journal pertain.

\title{
Killing two birds with one stone? Association between tobacco and alcohol
}

\section{consumption}

Authors: Ana Maria Reis ${ }^{a, d}$, Carlota Quintal $^{a, b}$ and Óscar Lourenço ${ }^{a, c}$

\author{
a University of Coimbra, FEUC, Av Dias da Silva 165, 3004-512 Coimbra, Portugal \\ ${ }^{b}$ CEISUC, CeBER and Faculty of Economics, University of Coimbra, Coimbra, Portugal. \\ ${ }^{c}$ CeBER and Faculty of Economics, University of Coimbra, Coimbra, Portugal \\ d Portuguese Health Regulation Authority (ERS) \\ ${ }^{*}$ Corresponding author: E-mail address: anamariacpr@hotmail.com
}

Public Health. 2017 Dec 12; 154:136-143. doi: 10.1016/j.puhe.2017.10.019. [on dec 21 2017] 


\section{Abstract}

Objectives: Tobacco and excessive alcohol consumption are addictive behaviours, listed among the 10 leading risk factors that cause death and disability in the world, and health consequences are greater if their consumption is combined. There is sparse empirical evidence on the variables that influence the simultaneous consumption of tobacco and alcohol. This study aims to identify the variables that influence the joint decision to consume alcohol and tobacco, and that encourage drinkers to smoke.

Study Design: The sample includes Portuguese adults, mainly aged 50 years and over, extracted from SHARE, covering the year 2011.

Methods: We propose a bivariate probit model, which allows us to model simultaneously the two goods, accounting for potential correlation between smoking and drinking decisions.

Results: We identified the variables that influence joint consumption, and tobacco consumption among drinkers, which could be used as policy instruments to develop concerted policies. Prevention policies should focus on males, younger and more educated individuals, as well as on individuals with unhealthy eating habits, because these variables were statistically significant and increased joint consumption. In addition, these characteristics also should be regarded if we want to control tobacco consumption among alcohol consumers.

Conclusions: The analysis of the interdependence between alcohol and tobacco use presented in this paper may allow reducing their consumption with a common intervention, enabling policymakers to 'kill two birds with one stone' and to achieve extended health and economic gains.

Keywords: Health behaviours; Addiction; Joint consumption; Bivariate probit. 


\section{Introduction}

Tobacco and alcohol are both health risk behaviours, related to negative health outcomes $^{1}$, listed among the top 10 leading causes of death and disability-adjusted life year (DALYs), in 2004². Tobacco causes approximately 6 million deaths each year ${ }^{3}$, which are projected to increase to 8.3 million in $2030^{4}$, and deaths related to alcohol were estimated to achieve 3.3 million, in $2012^{5}$. Moreover, alcohol and tobacco when used together increase the risk of some types of cancer and cardiovascular diseases, more than the use of either drug alone ${ }^{6-10}$. Therefore, if a combined policy is adopted, the expected health gains will exceed the sum of two separate interventions, focused on each good, which justify a study on the interdependence between goods. Although this is a worldwide problem, Portugal was, in 2012 , the $10^{\text {th }}$ country with the highest level of alcohol consumption ${ }^{11}$, and the $22^{\text {nd }}$ in percentage of daily smokers ${ }^{12}$.

While tobacco consumption is associated with negative health effects ${ }^{13,14}$, and a large proportion of smokers become addicted to nicotine ${ }^{15}$, alcohol use is socially acceptable if consumed moderately, and the negative health effects arise from overuse or misuse ${ }^{16}$. The social unacceptability of smoking has increased ${ }^{17}$, combined with smoker-related stigmatization and self-stigma ${ }^{17-19}$, but alcohol discrimination arise solely from alcohol misuse, which is from heavy drinking ${ }^{20}$.

Tobacco use is responsible for more than half a trillion dollars of economic losses every year ${ }^{3}$. The economic burden of alcohol was estimated to equate between 853.64 million dollars and 234,854 million dollars, considering total costs on 12 selected countries, including Portugal ${ }^{21}$. These behaviours also include social losses, such as health risks of second-hand tobacco smoke and harm done to their foetuses by pregnant women who smoke and drink excessively ${ }^{16}$, and are related to craving experiences, self-control, anxiety and psychosocial distress ${ }^{22-25}$.

Manning et al. (1989) estimated the negative externalities that smokers and drinkers impose on others. Considering that non-smokers subsidise smokers' medical care but smokers subsidise non-smokers' pensions and nursing home payments, these authors concluded that, on balance, smokers pay their own way at the current level of excise taxes on cigarettes, but the same is not true for drinkers, whose taxes cover only about half the costs imposed on others ${ }^{26}$. 
These two goods also share a potential addictive nature. The theoretical models focusing on addictive substances' demand - the myopic addiction model and the rational addiction model ${ }^{27}$ - do not account for the possibility of consuming tobacco and alcohol together. However the rational addiction model implies the common view that present-oriented individuals are potentially more addicted to harmful goods than future-oriented individuals' ${ }^{28}$, and more farsighted individuals will be more responsive to perceived future consequences of consuming hazardous goods ${ }^{29}$. Considering the myopic individuals, if the individual consumes one harmful good, because he prefers the present benefits rather than avoiding future negative consequences, he is likely to adopt other unhealthy behaviours that will give him a present reward. Therefore, it is important to analyse the potential connection between health-related behaviours.

The literature that considers the inter-relationship between alcohol and tobacco consumption is mainly focused on the price as the central variable and tests the complementarity between them based on cross-price elasticities. Various authors concluded that tobacco and alcohol are complements ${ }^{30-36}$. This complementarity between goods involves that greater utility is achieved when used together, associated with a combined 'reward effect' that is qualitatively different from the effects of either good consumed alone ${ }^{37,38}$.

On the other hand, there is an extensive body of literature analysing the consumption of tobacco and alcohol separately. In a case study that was previously developed, the prevalence of smoking among alcohol dependents was $88 \%{ }^{39}$. The importance of analysing the interdependence between goods was also discussed concerning smoking and obesity, leading to the conclusion that a single policy tool can reduce both ${ }^{40}$.

The existing evidence supports the role of socioeconomic variables explaining alcohol and tobacco consumption ${ }^{32,41-44}$. Manrique and Jensen (2004) applied a bivariate probit to estimate the joint use of alcohol and tobacco, in Spain, and concluded that there is a correlation between smoking and drinking ${ }^{43}$. Zhao and Harris (2004) results indicate a strong correlation between consumption of tobacco, alcohol and marijuana. Finally, Bussu and Detotto (2015), considering a sample of gamblers 
with a mean age of 35 years, in Sardinia, estimated a multivariate probit model that did not show a bidirectional effect between gambling, alcohol and drugs, but revealed a unidirectional effect between gambling and smoking ${ }^{45}$. Although these authors have analysed the variables that influence alcohol and tobacco consumption, they estimate neither the determinants of joint consumption nor the probabilities of consuming tobacco conditional on being a drinker.

In sum, few studies control for potential correlation between the disturbance terms of the tobacco and alcohol equations, which can bias the obtained results. Additionally, as far as we know, the effects of socioeconomic factors that influence the decision to use both alcohol and tobacco, and that encourage drinkers to smoke were not the focus of previous studies. In Portugal, there is no empirical evidence on this topic, besides some descriptive statistics applied to tobacco and alcohol consumption $^{46}$, and we wanted also to fill this gap.

Following this line, the aim of this study is to identify the variables that influence the joint decision to consume alcohol and tobacco, and that encourage drinkers to smoke, accounting for potential correlation between the decisions of smoking and hazardous drinking. We propose a bivariate probit model to analyse the variables that affect alcohol and tobacco consumption. This model presents advantages over other specifications because it allows detecting correlations between the error terms of two equations - in this study between tobacco and alcohol equations - and controls for potential reverse causality problems, given that alcohol can affect tobacco consumption, but alcohol consumption can also influence tobacco consumption. In addition to the estimates of the model, we also computed the joint probabilities and conditional probabilities for identifying the variables that stimulated the consumption of both goods, and the variables that motivated alcohol consumers to smoke.

Considering that alcohol and tobacco consumption are both health risk behaviours that share also an addictive nature, and that health consequences may be greater if their consumption is combined, it is of major relevance to analyse the links between alcohol and tobacco consumption. From the health policy perspective, if 
these links are neglected, and not studied from a methodological and conceptual point of view, as we propose in our analysis, the policy could be less efficient.

The remainder of the paper is structured as follows. Section 2 explains the methodology, dataset and variables; the estimation's results are described in Section 3 ; in section 4 the results are discussed and the main conclusions are presented.

\section{Methods}

We used a sample of Portuguese adults, mainly aged 50 years and over, extracted from Survey of Health, Ageing and Retirement in Europe (SHARE) Wave 4, a panel database of micro data on health, socioeconomic status and family networks ${ }^{47-}$ 51, using 2011 data. The sample covered 1103 individuals and their characteristics are described in Table 2. Despite the sample median age is 63.8 , compared with the average age of 41.8 in 2011 in Portugal ${ }^{52}$, it is representative of the Portuguese individuals aged 45 and over. Concerning socioeconomic characteristics, the sample approaches the 2011 Portuguese annual gross disposable income per inhabitant, $€ 11,531^{53}$, as well as occupation, as far as $48.0 \%$ of the Portuguese population aged 45 and over was retired, and $12.1 \%$ of the working population was unemployed ${ }^{52}$. In this sample, $46.3 \%$ of the respondents completed primary education, and $10.7 \%$ the basic education, which are similar characteristics of the adults Portuguese aged 45 and over, $45.0 \%$ of whom completed primary education and $11.3 \%$ basic education ${ }^{52}$. In what concerns to the marital status, $6.8 \%$ were divorced and $78.7 \%$ were married. This is not very different from the Portuguese profile, where $7.6 \%$ and $68.2 \%$, were respectively divorced and married ${ }^{52}$. However, this sample has an overrepresentation of men (59.2\% in our sample, compared with $45 \%$ in Portugal) ${ }^{54}$.

We were interested in studying the potential correlation between alcohol and tobacco, to evaluate the extent to which the individuals make related decisions about these two goods. Our measure of tobacco consumption is a binary variable that takes the value 1 if the individual was a current smoker at the time of the interview. In what concerns drinking patterns, choosing a measure of excessive alcohol consumption is not straightforward. As described previously, some levels of alcohol consumption are 
socially accepted and do not comprise adverse consequences, which derive from excessive consumption. Consequently, it is difficult to determine the accuracy of any given variable intended to capture harmful alcohol consumption.

In this study, we adopted a measure commonly used, 'hazardous drinking', defined as having three or more drinks in one day, in line with previous authors ${ }^{55}$, and also taking as a reference the drinking guidelines, which defined hazardous drinking limit as the limit above which people are at risk for their health ${ }^{56}$.

From the contingency table presented below, (Table 1) $14.2 \%$ of the respondents were current smokers, $22.3 \%$ were hazardous drinkers and $4.6 \%$ were smokers and hazardous drinkers. The implementation of a Person's Chi-square test led to the rejection of the null hypothesis ( $p$-value $=0.001$ ), suggesting that these variables are statistically dependent.

Table 1 Contingency table

\begin{tabular}{cccc}
\hline \multicolumn{4}{c}{ Hazardous drinking } \\
\hline Smoke & 0 & 1 & Total \\
0 & 751 & 195 & 946 \\
1 & 106 & 51 & 157 \\
Total & 857 & 246 & 1103 \\
\hline \multicolumn{5}{c}{ Pearson $\chi^{2}(1)=(10.950)^{* *}$}
\end{tabular}

Given the purpose of analysing the individual's decisions regarding the consumption of alcohol and tobacco within the same empirical framework, and the binary nature of the dependent variables, a bivariate probit model provides the appropriate specification. Moreover, this model also allowed estimating the correlation between the error terms of the two equations and controls for the potential bias that may arise from correlation. The bivariate probit model estimates a system of equations (equation 1 ):

$$
\text { (1) }\left\{\begin{array}{c}
y_{1, i}^{*}=\alpha_{i}+X^{\prime}{ }_{i} \beta_{1}+\mu_{1}, y_{1}=1 \text { if } y_{1}^{*}>0,0 \text { otherwise } \\
y_{2, i}^{*}=\phi_{i}+X^{\prime}{ }_{i} \beta_{2}+\mu_{2}, y_{2}=1 \text { if } y_{2}^{*}>0,0 \text { otherwise }
\end{array}\right.
$$

Where $\mathrm{y}_{1}$ is a binary variable that takes the value 1 if the individual ' $\mathrm{i}$ ' is a current smoker $\left(y_{1}^{*}>0\right)$, and $y_{2}$ is a binary variable that takes the value 1 if the individual consumes excessive alcohol $\left(\mathrm{y}_{2}^{*}>0\right)$. $\mu_{1}$ and $\mu_{2}$ are the error terms of each 
equation, and the correlation between these two error terms is expected to be different from zero if the behaviours are correlated. A vector of explanatory variables (X) associated with individual's characteristics is included in both equations, and $\beta_{1}$ and $\beta_{2}$ are the coefficients of each explanatory variable.

The bivariate probit model is a 'joint model for two binary outcomes that generalises the index function model from one latent variable to two latent variables that may be correlated'57. If the correlation between $\mu_{1}$ and $\mu_{2}$ is zero $(\rho=0)$, the model is equivalent to estimate two separate probit models, one for each part of equation 1.

According to Greene (2003), after the estimation of the bivariate probit model, we may compute several behavioural index functions of the covariates, and each of which has the potential to unveil the marginal effects of observing specific probabilities. The unconditional mean functions are given by the univariate probabilities (equation 2):

$$
\text { (2) } P\left[y_{j} \mid X\right]=\phi\left(X^{\prime} \gamma_{j}\right), j=1,2
$$

Where $\gamma_{1}$ contains all the nonzero elements of $\beta_{1}$ and $\gamma_{2}$ is defined likewise ${ }^{58}$.

To answer the main question of this study, given that we were interested in identifying the variables that are joint determinants of tobacco and alcohol consumption, we estimate the joint probabilities of tobacco and alcohol consumption, which is $\mathrm{y}_{1}=1$ and $\mathrm{y}_{2}=1$. The probabilities that enter the likelihood function are (equation 3):

$$
\text { (3) } P\left(y_{1}=1, y_{2}=1 \mid x\right) \text {, }
$$

Using this function, we can also estimate the impact of the covariates in the conditional probability of consuming tobacco, given that the individual is an alcohol consumer (equation 4):

$$
\text { (4) } P\left(y_{1}=1\left|y_{2}=1\right| X\right) \text {, }
$$

The explanatory variables chosen were age, gender, education, marital status, occupation, income, other health-related behaviours (physical activity and eating habits) and depression. We also included a variable that counts the number of 
diseases, as a proxy for worse health status. Considering the typical assumption that individuals have identical risk preferences, which is, attitudes towards financial risk should affect consumers' willingness to take a risk in a variety of situations, including health $^{59}$, a measure of financial risk aversion was added, as a proxy for health risk aversion. This assumption is supported by previous findings that financial risk-averse individuals are more likely than the risk-prone to avoid health risks, related to exposure to chronical conditions and mortality risks ${ }^{59,60}$. The correlations between variables were calculated in order to select an adequate model, namely Corr (Unemployment, Income) = -0.006; Corr (Physical activity, Diseases) $=-0.172$; Corr (Physical activity, Vegetables) $=-0.048$. Given that the correlations are low all the variables were included in the model. Table 2 presents variables description and some statistics. Stata 13 was used for all analyses.

Table 2 Variables description and statistics

\begin{tabular}{|c|c|c|c|}
\hline Variables & Description & Mean & Std. Dev. \\
\hline \multicolumn{4}{|l|}{ Dependent variables } \\
\hline Smoke & $\begin{array}{l}\text { Binary variable. } 1 \text { if current smoker at the } \\
\text { time of the interview, } 0 \text { otherwise. }\end{array}$ & 0.142 & 0.350 \\
\hline Hazardous drinking & $\begin{array}{l}\text { Binary variable. } 1 \text { if respondent has taken } \\
\text { three or more drinks per day, on the days } \\
\text { respondent drank, in three months before } \\
\text { the questionnaire. }\end{array}$ & 0.223 & 0.416 \\
\hline \multicolumn{4}{|c|}{ Independent variables } \\
\hline Male & Binary variable. 1 if male. & 0.592 & 0.492 \\
\hline Age & $\begin{array}{l}\text { The number of years that the respondent } \\
\text { has lived. }\end{array}$ & 63.805 & 9.199 \\
\hline Education & $\begin{array}{l}\text { Number of years the respondent has been } \\
\text { in full-time education. }\end{array}$ & 6.490 & 4.455 \\
\hline Married & Binary variable. 1 if married. & 0.787 & 0.410 \\
\hline Divorced & Binary variable. 1 if divorced. & 0.068 & 0.252 \\
\hline Widowed & Binary variable. 1 if widowed. & 0.073 & 0.259 \\
\hline Unemployed & Binary variable. 1 if unemployed. & 0.071 & 0.256 \\
\hline Retirement & Binary variable. 1 if retired. & 0.561 & 0.496 \\
\hline Risk aversion & $\begin{array}{l}\text { Financial risk aversion as a proxy for health } \\
\text { risk aversion. } 1 \text { if the individual is not willing } \\
\text { to take any financial risks. }\end{array}$ & 0.882 & 0.323 \\
\hline Income & $\begin{array}{l}\text { Value of annual income previous year, after } \\
\text { taxes. }\end{array}$ & 9905.340 & 20361.45 \\
\hline
\end{tabular}




\begin{tabular}{|c|c|c|c|}
\hline Physical Activity & $\begin{array}{l}\text { Binary variable. } 1 \text { if the individual does } \\
\text { physical exercise more than once a month. }\end{array}$ & 0.480 & 0.500 \\
\hline Vegetables & $\begin{array}{l}\text { In a regular week, how often the } \\
\text { respondent consumes fruits or vegetables. } \\
\text { Categorical variable 1) Every day; 2) 3-6 } \\
\text { times a week; } 3 \text { ) Twice a week; 4) Once a } \\
\text { week; 5) Less than once a week. }\end{array}$ & 1.165 & 0.497 \\
\hline Depression & $\begin{array}{l}\text { Answer to the question: 'there been a time } \\
\text { or times }[\ldots] \text { when you suffered from } \\
\text { symptoms of depression which lasted at } \\
\text { least two weeks?'. } 1 \text { if the answer is yes. }\end{array}$ & 0.300 & 0.459 \\
\hline Diseases & $\begin{array}{l}\text { Number of diseases (among the following } \\
\text { list: heart problems; high blood pressure or } \\
\text { hypertension; high blood cholesterol; } \\
\text { Stroke or cerebral vascular disease; } \\
\text { diabetes or high blood sugar; chronic lung } \\
\text { disease; cancer or malignant tumour; } \\
\text { stomach or duodenal ulcer, peptic ulcer). }\end{array}$ & 1.309 & 1.223 \\
\hline
\end{tabular}

\section{Results}

Table 3 displays the estimated results of the bivariate probit model that was presented in the last section. In addition to the coefficients, the average marginal effects on the probabilities of smoking and drinking are shown. These are the effects of unitary variations of each explanatory variable on tobacco and excessive alcohol consumption probabilities. Given that the correlation coefficient between the error terms of the two equations (equation 1$), \rho_{\text {Alc,Toc }}=0.085(p$-value $=0.260)$, is not statistically significant, low correlations between the unobservable error terms of these behaviours were found. Therefore, we also could estimate the equations of alcohol and tobacco use separately, with two separate probit models.

In this study, we have found that age had a negative statistically significant effect on smoking and also on drinking. According to earlier findings of Manrique and Jensen (2004), focused on a sample of adult individuals with median age 49.6 years, older household heads had a lower probability of consuming tobacco and alcohol. Cameron and Williams (2001) showed that individuals aged 40 years old and over were both less likely to have smoked and less likely to drink than those under 20 years. However, Su and Yen (2000) found a positive effect of age on wine consumption but no significant effect on beer consumption. 
In our model, gender had a statistically significant effect on both behaviours. Men were found to be more likely to smoke and also more likely to drink. Previous studies also concluded that men were more likely to consume both alcohol and tobacco $^{30,41,43}$, as well as alcohol ${ }^{32,61,62}$ or tobacco separately ${ }^{63-66}$.

In this study, we have also found that individuals with more years of education were more likely to smoke, and less likely to take three or more drinks per day. Decker and Schwartz (2000) obtained different results, concluding that education increased both the probabilities of smoking and drinking, in a subsample of individuals with average age 45 . However, other studies shown that adults who hold a degree were less likely to smoke whereas the opposite occurred to excessive alcohol consumption ${ }^{30}$.

Regarding the marital status, being married significantly reduced the probability of smoking by $15.7 \%$, when compared with single respondents, but did not affect alcohol consumption decisions, similar to what was found by Cameron and Williams (2001). However, Decker and Schwartz (2000) shown that being married reduced the consumption of the two goods. We have also found that widowers were less likely to smoke but more likely to drink.

Considering occupation, unemployed and retirement situation did not seem to influence tobacco and alcohol consumption, and Nayga and Capps (1994) also concluded employed individuals did not significantly consume less alcohol than unemployed individuals. Our results are different from those obtained by Su and Yen (2000), who concluded that employed individuals were more likely to consume alcohol, and Manrique and Jensen (2004) have found in their study that employment reduced the smoking probability. In our estimates, an increase in income reduced the probability of consuming tobacco, but the marginal effect was small.

In relation to health-related habits, we have found that respondents that reported eating fruit or vegetables less frequently had higher probability of consuming tobacco and that the practice of physical activities was associated with reduced tobacco consumption. Moreover, the number of diseases was associated with reduced consumption of tobacco but had not a statistically significant effect on alcohol consumption. 
Table 3 Bivariate probit smoking and hazardous drinking

\begin{tabular}{|c|c|c|c|c|}
\hline \multirow[b]{2}{*}{ Variables } & \multicolumn{2}{|c|}{ Smoke } & \multicolumn{2}{|c|}{ Hdrink } \\
\hline & Coefficient & Mg. effect & Coefficient & Mg. effect \\
\hline \multirow[t]{2}{*}{ Male } & 0.751 & 0.130 & 1260 & 0.298 \\
\hline & $(0.130)^{* * *}$ & $(0.020)^{* * *}$ & $(0.122)^{* * *}$ & $(0.024)^{* * *}$ \\
\hline \multirow[t]{2}{*}{ Age } & -0.036 & -0.007 & -0.024 & -0.006 \\
\hline & $(0.009)^{* * *}$ & $(0.002)^{* * *}$ & $(0.007)^{* * *}$ & $(0.002)^{* * *}$ \\
\hline \multirow[t]{2}{*}{ Unemployed } & 0.339 & 0.072 & 0.179 & 0.048 \\
\hline & $(0.192)^{*}$ & $(0.045)$ & $(0.186)$ & $(0.052)$ \\
\hline \multirow[t]{2}{*}{ Retirement } & 0.152 & 0.028 & 0.003 & 0.001 \\
\hline & $(0.149)$ & $(0.027)$ & $(0.131)$ & $(0.034)$ \\
\hline \multirow[t]{2}{*}{ Education } & 0.068 & 0.013 & -0.021 & -0.005 \\
\hline & $(0.013)^{* * *}$ & $(0.002)^{* * *}$ & $(0.012)^{*}$ & $(0.003)^{*}$ \\
\hline \multirow[t]{2}{*}{ Married } & -0.696 & -0.157 & 0.089 & 0.023 \\
\hline & $(0.175)^{* * *}$ & $(0.045)^{* * *}$ & $(0.192)$ & $(0.048)$ \\
\hline \multirow[t]{2}{*}{ Divorced } & -0.239 & -0.041 & -0.088 & -0.022 \\
\hline & $(0.237)$ & $(0.036)$ & $(0.265)$ & $(0.065)$ \\
\hline \multirow[t]{2}{*}{ Widower } & -0.579 & -0.084 & 0.521 & 0.149 \\
\hline & $(0.323)^{*}$ & $(0.035)^{* *}$ & $(0.272)^{*}$ & $(0.083)^{*}$ \\
\hline \multirow[t]{2}{*}{ Risk aversion } & -0.045 & -0.008 & -0.050 & -0.013 \\
\hline & $(0.160)$ & $(0.031)$ & $(0.146)$ & $(0.038)$ \\
\hline \multirow[t]{2}{*}{ Income } & $-1.23 \mathrm{E}-05$ & $-2.28 e-06$ & $-3.74 e-06$ & $-9.61 e-07$ \\
\hline & $(4.65 e-06)^{* * *}$ & $(8.63 e-07)^{* * *}$ & ( $2.74 \mathrm{e}-06)$ & (7.03e-07) \\
\hline \multirow[t]{2}{*}{ Physical activity } & -0.235 & -0.044 & 0.131 & 0.034 \\
\hline & $(0.109)^{* *}$ & $(0.020)^{* *}$ & $(0.095)$ & $(0.024)$ \\
\hline \multirow[t]{2}{*}{ Vegetables } & 0.178 & 0.033 & 0.044 & 0.011 \\
\hline & $(0.091)^{*}$ & $(0.017)^{* *}$ & $(0.087)$ & $(0.022)$ \\
\hline \multirow[t]{2}{*}{ Depression } & 0.086 & 0.016 & -0.025 & -0.006 \\
\hline & $(0.123)$ & $(0.024)$ & $(0.111)$ & $(0.028)$ \\
\hline \multirow[t]{2}{*}{ Diseases } & -0.113 & -0.021 & -0.060 & -0.015 \\
\hline & $(0.049)^{* *}$ & $(0.009)^{* *}$ & $(0.041)$ & $(0.010)$ \\
\hline \multirow[t]{2}{*}{ Constant } & 0.808 & & -0.073 & \\
\hline & $(0.572)$ & & $(0.509)$ & \\
\hline$\rho$ & $\begin{array}{l}0.085 \\
(0.075)\end{array}$ & & & \\
\hline
\end{tabular}

$\mathrm{N}=1057$. Standard errors in parentheses. ${ }^{* * *} \mathrm{p}<0.01 .{ }^{* *} \mathrm{p}<0.05 .{ }^{*} \mathrm{p}<0.1$.

In Table 4, the average marginal effects for the joint probabilities of smoking and drinking, which is $\mathrm{P}\left(\mathrm{y}_{1}=1, \mathrm{y}_{2}=1 \mid \mathrm{X}\right)$ (equation 3 ), are shown. This estimation enabled us to identify the variables that influenced the decision to use both alcohol and tobacco. We have conducted robustness checks using three separate models: The 
first model only covers the socioeconomic characteristics (M1), the second includes health related habits and measures of physical and mental health (M2), and M3 shows the complete model, with all variables that we described before. Given that the three models provided consistent results, we describe the complete model's conclusions.

As it can be seen in Table 4, age reduced the joint probability of smoking and drinking, as well as being married, when compared to single individuals. Men, compared with women, were more likely to smoke and also drink. These results are in accordance with Manrique and Jensen (2004) findings, which concluded that age reduced the consumption of tobacco as well as the consumption of alcohol. These authors has also shown that being male had a positive effect on the alcohol's equation and on the tobacco's equation. Although these authors applied a bivariate probit model, they did not estimate the joint probabilities of consuming the two goods, but only the probabilities of consuming each good, separately.

Occupation did not seem to influence combined consumption of alcohol and tobacco, while higher income levels reduced this combined consumption, but with small marginal effect. The number of years of schooling increased the probability of combined consumption of tobacco and hazardous drinking. We have also found that respondents reporting eating fruit or vegetables less frequently had increased probability of tobacco consumption and hazardous drinking and that the number of diseases reduced this probability. This effect indicates that a worse health status reduces the probability of consuming these two goods.

Table 4 Marginal effects for the joint probabilities

\begin{tabular}{llll}
\hline Variables & M1 & M2 & M3 \\
\hline Male & 0.079 & 0.078 \\
& $(0.010)^{* * *}$ & $(0.010)^{* * *}$
\end{tabular}




\begin{tabular}{|c|c|c|c|}
\hline \multirow[t]{2}{*}{ Age } & -0.003 & & -0.003 \\
\hline & $(0.001)^{* * *}$ & & $(0.001)^{* * *}$ \\
\hline \multirow[t]{2}{*}{ Unemployed } & 0.035 & & 0.032 \\
\hline & $(0.020)^{*}$ & & $(0.020)$ \\
\hline \multirow[t]{2}{*}{ Retirement } & 0.007 & & 0.008 \\
\hline & $(0.010)$ & & $(0.010)$ \\
\hline \multirow[t]{2}{*}{ Education } & 0.003 & & 0.003 \\
\hline & $(0.001)^{* * *}$ & & $(0.001)^{* * *}$ \\
\hline \multirow[t]{2}{*}{ Married } & -0.045 & & -0.038 \\
\hline & $(0.020)^{* *}$ & & $(0.019)^{* *}$ \\
\hline \multirow[t]{2}{*}{ Divorced } & -0.020 & & -0.015 \\
\hline & $(0.013)$ & & $(0.014)$ \\
\hline \multirow[t]{2}{*}{ Widower } & -0.017 & & -0.014 \\
\hline & $(0.017)$ & & $(0.018)$ \\
\hline \multirow[t]{2}{*}{ Risk aversion } & -0.005 & & -0.005 \\
\hline & $(0.012)$ & & $(0.012)$ \\
\hline \multirow[t]{2}{*}{ Income } & $-9.12 e-07$ & & $-8.50 e-07$ \\
\hline & $(3.05 e-07)^{* * *}$ & & $(2.99 \mathrm{e}-07)^{* * *}$ \\
\hline \multirow[t]{2}{*}{ Physical activity } & & 0.004 & -0.007 \\
\hline & & $(0.008)$ & $(0.008)$ \\
\hline \multirow[t]{2}{*}{ Vegetables } & & 0.023 & 0.012 \\
\hline & & $(0.007)^{* * *}$ & $(0.007)^{*}$ \\
\hline \multirow[t]{2}{*}{ Depression } & & -0.006 & 0.004 \\
\hline & & $(0.008)$ & (0.009) \\
\hline \multirow[t]{2}{*}{ Diseases } & & -0.013 & -0.009 \\
\hline & & $(0.004)^{* * *}$ & $(0.003)^{* * *}$ \\
\hline
\end{tabular}

As we were interested in shedding some light on health policy implications, combined treatment for both addictions may lead to more favourable outcomes, and treatment of smoking habit in alcoholics could be advantageous ${ }^{37}$. Therefore, it is also useful to understand how the probability of smoking is affected by the explanatory variables considered, in the subsample of alcohol consumers. Conditional probabilities of experience tobacco consumption among alcohol consumers were also estimated, $P\left(y_{1}=1\left|y_{2}=1\right| X\right)$ (equation 4$)$, and results are presented in Table 5.

The results show that age reduced smoking probability among alcohol consumers. Moreover, according to our estimates, gender influences tobacco consumption in the subsample of alcohol consumers, revealing that men who drink 
were more likely to smoke. Being married and widower, compared with being single, influenced tobacco consumption among excessive alcohol consumers, reducing the probability of being a smoker. Drinkers with more years of schooling were more likely to smoke. Alcohol consumers with higher income had lower smoking probability, but the marginal effect was low. The other socioeconomic characteristics, namely unemployment and retirement situation did not influence tobacco consumption in the subsample of alcohol consumers. In this subsample, individuals with less healthy eating habits (who consume fruit or vegetables less frequently) and who were sedentary were more likely to consume tobacco, which suggests a predisposition to adopt unhealthy habits. Moreover, the number of diseases was associated with reduced tobacco consumption, among alcohol consumers.

Table 5 Conditional predicted probabilities of smoking, marginal effects

\begin{tabular}{lccc}
\hline Variables & M1 & M2 & M3 \\
\hline Male & 0.127 & & 0.130
\end{tabular}




\begin{tabular}{|c|c|c|c|}
\hline & $(0.022)^{* * *}$ & & $(0.023)^{* * *}$ \\
\hline \multirow[t]{2}{*}{ Age } & -0.008 & & -0.007 \\
\hline & $(0.002)^{* * *}$ & & $(0.002)^{* * *}$ \\
\hline \multirow[t]{2}{*}{ Unemployed } & 0.094 & & 0.076 \\
\hline & $(0.051)^{*}$ & & (0.049) \\
\hline \multirow[t]{2}{*}{ Retirement } & 0.034 & & 0.031 \\
\hline & $(0.031)$ & & $(0.030)$ \\
\hline \multirow[t]{2}{*}{ Education } & 0.015 & & 0.014 \\
\hline & $(0.003)^{* * *}$ & & $(0.003)^{* * *}$ \\
\hline \multirow[t]{2}{*}{ Married } & -0.194 & & -0.173 \\
\hline & $(0.052)^{* * *}$ & & $(0.051)^{* * *}$ \\
\hline \multirow[t]{2}{*}{ Divorced } & -0.062 & & -0.044 \\
\hline & $(0.038)$ & & $(0.041)$ \\
\hline \multirow[t]{2}{*}{ Widower } & -0.107 & & -0.099 \\
\hline & $(0.040)^{* * *}$ & & $(0.041)^{* *}$ \\
\hline \multirow[t]{2}{*}{ Risk aversion } & -0.008 & & -0.009 \\
\hline & $(0.035)$ & & $(0.034)$ \\
\hline \multirow[t]{2}{*}{ Income } & $-2.69 e-06$ & & $-2.49 e-06$ \\
\hline & $(9.91 \mathrm{e}-07)^{* * *}$ & & $(9.69 \mathrm{e}-07)^{* *}$ \\
\hline \multirow[t]{2}{*}{ Physical activity } & & -0.048 & -0.050 \\
\hline & & $(0.027)^{*}$ & $(0.023)^{* *}$ \\
\hline \multirow[t]{2}{*}{ Vegetables } & & 0.071 & 0.036 \\
\hline & & $(0.023)^{* * *}$ & $(0.019)^{*}$ \\
\hline \multirow[t]{2}{*}{ Depression } & & 0.053 & 0.018 \\
\hline & & $(0.031)^{*}$ & $(0.026)$ \\
\hline \multirow[t]{2}{*}{ Diseases } & & -0.048 & -0.023 \\
\hline & & $(0.012)^{* * *}$ & $(0.010)^{* *}$ \\
\hline
\end{tabular}

\section{Discussion}

Tobacco and excessive alcohol consumption are both responsible for health, economic and social costs. In addition to the common nature of health risk behaviours, tobacco and alcohol are addictive goods. Considering that health risks are greater if their consumption is combined, it is relevant to better understand the links between these behaviours.

This study revealed that tobacco consumption and hazardous drinking were not related, which suggests individuals do not share a common addictive behaviour 
predisposition. The individuals who drank three or more drinks a day seemed to have different incentives when compared with current smokers. One possible explanation could be related with the different levels of addiction concerning tobacco use and the adopted measure of alcohol consumption. In spite of tobacco is being widely accepted as an addictive good, it is not easy to classify alcohol addiction. Alcohol consumption, per se, is not evidence of addiction and, in some cases, it can arise from social interaction rather than alcohol addiction.

Considering the obtained results, which made it possible to identify the individuals who were more likely to consume both goods, prevention policies should focus on males, younger and more educated individuals, as well as on individuals with unhealthy eating habits, because these variables were statistically significant and increased joint consumption. In addition, these characteristics also should be regarded if we want to control tobacco consumption, among alcohol consumers.

Some potential limitations of this study must be considered. First, the consumption spending on tobacco and alcohol was not available, given that the database used does not allow the identification of the type of beverages consumed or the brand of cigarettes. In addition, the ages at which respondents started smoking and drinking are unknown, preventing from identifying the history of consumption. Although the individuals in our sample are mainly aged 50 and over, this kind of sample can give an interesting perspective of adult's decisions throughout their lifetime, because we expect they already had thought about their smoking and drinking decisions. This sample's specificity should be taken into consideration and the results should be interpreted accordingly.

In sum, this work enabled to analyse alcohol and tobacco consumption together, identifying correlations between behaviours, and pointing out variables that could be used as policy instruments to develop concerted policies. This topic deserves further attention and investigation, namely from a policy perspective, given that prevention policies should take into account the links between behaviours ${ }^{67}$, and eventually disparities among different types of drinkers ${ }^{68}$. It could be useful to consider distinct measures of alcohol addiction, given that the limited available evidence suggests that the prevalence of tobacco use varies among levels of alcohol 
consumption $^{69}$. A better understanding and exploration of connections between addictive behaviours will enable policymakers to 'kill two birds with one stone' and to achieve extended health and economic gains. These potential links should not be neglected and should be further explored, contributing to a more efficient use of public resources. 


\section{References}

1. Kenkel D. Should you eat breakfast? Estimates from health production functions. Health Econ. 1995 Jan;4(1):15-29.

2. WHO. Global health risks: mortality and burden of disease attributable to selected major risks. Geneva, Switzerland: WHO; 2009. 62 p.

3. WHO. WHO report on the global tobacco epidemic, 2013 enforcing bans on tobacco advertising, promotion and sponsorship. Geneva: WHO; 2013.

4. Mathers C, Fat DM, Boerma JT, WHO, editors. The global burden of disease: 2004 update. Geneva: WHO; 2008. 146 p.

5. WHO. Global status report on alcohol and health, 2014. Geneva: WHO; 2014.

6. Castellsagué X, Munoz N, De Stefani E, Victora CG, Castelletto R, Rolón PA, et al. Independent and joint effects of tobacco smoking and alcohol drinking on the risk of esophageal cancer in men and women. Int J Cancer. 1999 Aug 27;82(5):65764.

7. Lee $\mathrm{C}-\mathrm{H}$, Lee J-M, Wu D-C, Hsu H-K, Kao E-L, Huang H-L, et al. Independent and combined effects of alcohol intake, tobacco smoking and betel quid chewing on the risk of esophageal cancer in Taiwan. Int J Cancer. 2005 Jan 20;113(3):475-82.

8. Pelucchi C, Gallus S, Garavello W, Bosetti C, La Vecchia C. Alcohol and tobacco use, and cancer risk for upper aerodigestive tract and liver: Eur J Cancer Prev. 2008 Aug;17(4):340-4.

9. U.S. Department of Health and Human Services. Reducing the Health Consequences of Smoking: 25 Years of Progress. A Report of the Surgeon General. Washington, DC: Government Printing Office; 1989. 89-8411 p.

10. Znaor A, Brennan P, Gajalakshmi V, Mathew A, Shanta V, Varghese C, et al. Independent and combined effects of tobacco smoking, chewing and alcohol drinking on the risk of oral, pharyngeal and esophageal cancers in Indian men. Int J Cancer. 2003 Jul 10;105(5):681-6.

11. Sassi F. Tackling Harmful Alcohol Use: Economics and Public Health Policy [Internet]. Paris: OECD Publishing; 2015 [cited 2015 May 18]. Available from: http://www.oecd-ilibrary.org/social-issues-migration-health/tackling-harmfulalcohol-use_9789264181069-en

12. OECD. OECD Health Statistics 2014. How does Portugal compare? OECD; 2014.

13. Ippolito P. Information and the life cycle consumption of hazardous goods. Econ Inq. 1981 Oct;19(4):529-58.

14. Gajalakshmi V, Kanimozhi V. Tobacco Chewing and Adult Mortality: a Casecontrol Analysis of 22,000 Cases and 429,000 Controls, Never Smoking Tobacco and Never Drinking Alcohol, in South India. Asian Pac J Cancer Prev. 2015 Mar 4;16(3):1201-6. 
15. Chaloupka F, Grossman M, Saffer $H$. The effects of price on alcohol consumption and alcohol-related problems. Alcohol Res Health. 2002;26(1):22-34.

16. Grossman M, Sindelar JL, Mullahy J, Anderson R. Policy Watch: Alcohol and Cigarette Taxes. J Econ Perspect. 1993 Nov;7(4):211-22.

17. Stuber J, Galea S, Link BG. Smoking and the emergence of a stigmatized social status. Soc Sci Med. 2008 Aug;67(3):420-30.

18. Bell K, Salmon A, Bowers M, Bell J, McCullough L. Smoking, stigma and tobacco "denormalization": Further reflections on the use of stigma as a public health tool. A commentary on Social Science \&amp; Medicine's Stigma, Prejudice, Discrimination and Health Special Issue (67: 3). Soc Sci Med. 2010 Mar;70(6):7959.

19. Evans-Polce RJ, Castaldelli-Maia JM, Schomerus G, Evans-Lacko SE. The downside of tobacco control? Smoking and self-stigma: A systematic review. Soc Sci Med. 2015 Nov;145:26-34.

20. Gilbert PA, Zemore SE. Discrimination and drinking: A systematic review of the evidence. Soc Sci Med. 2016 Jul;161:178-94.

21. Thavorncharoensap M, Teerawattananon $\mathrm{Y}$, Yothasamut J, Lertpitakpong C, Chaikledkaew $U$. The economic impact of alcohol consumption: a systematic review. Subst Abuse Treat Prev Policy. 2009;4(1):20.

22. Bottlender $\mathrm{M}$, Soyka $\mathrm{M}$. Impact of craving on alcohol relapse during, and 12 months following, outpatient treatment. Alcohol Alcohol. 2004 Jul 1;39(4):35761.

23. Vieten C, Astin JA, Buscemi R, Galloway GP. Development of an Acceptance-Based Coping Intervention for Alcohol Dependence Relapse Prevention. Subst Abuse. 2010 Apr 20;31(2):108-16.

24. Leeman RF, Bogart D, Fucito LM, Boettiger CA. "Killing Two Birds with One Stone": Alcohol Use Reduction Interventions with Potential Efficacy at Enhancing Selfcontrol. Curr Addict Rep. 2014 Mar;1(1):41-52.

25. Daly M, Delaney L, Baumeister RF. Self-control, future orientation, smoking, and the impact of Dutch tobacco control measures. Addict Behav Rep. 2015 Jun;1:8996.

26. Manning W, Keeler E, Newhouse J, Sloss E, Wasserman J. The taxes of sin. Do smokers and drinkers pay their way? JAMA. 1989 Mar 17;261(11):1604-9.

27. Chaloupka F, Warner K. The Economics of Smoking. In: Handbook of Health Economics. Amsterdam: J. Newhouse and A. Cuyler; 2000.

28. Becker G, Murphy K. A theory of rational addiction. J Polit Econ. 1988;96(4):675700.

29. Chaloupka F, Tauras J, Grossman M. Economic models of addiction and applications to cigarette smoking and other substance abuse. Chicago: University of Illinois; 1999. pp. 1-27. 
30. Cameron L, Williams J. Cannabis, Alcohol and Cigarettes: Substitutes or Complements? Econ Rec. 2001 Mar;77(236):19-34.

31. Dee TS. The complementarity of teen smoking and drinking. J Health Econ. 1999 Dec;18(6):769-93.

32. Decker S, Schwartz AE. Cigarettes and Alcohol: Substitutes or Complements? 2000 Feb;National Bureau of Economic Research, Working Paper No. 7535.

33. Zhao X, Harris M. Demand for Marijuana, Alcohol and Tobacco: Participation, Levels of Consumption and Cross-equation Correlations. Econ Rec. 2004;80(251):394-410.

34. Bask M, Melkersson M. Rationally addicted to drinking and smoking? Appl Econ. 2004 Mar;36(4):373-81.

35. Pierani P, Tiezzi S. Addiction and interaction between alcohol and tobacco consumption. Empir Econ. 2009 Sep;37(1):1-23.

36. Tauchmann H, Lenz S, Requate T, Schmidt CM. Tobacco and alcohol: complements or substitutes?: A structural model approach to insufficient price variation in individual-level data. Empir Econ. 2013 Aug;45(1):539-66.

37. Drobes D. Concurrent Alcohol and Tobacco Dependence. Mechanisms and Treatment. Alcohol Res Health. 2002;26(2):136-42.

38. Tizabi Y, Bai L, Copeland RL, Taylor RE. Combined effects of systemic alcohol and nicotine on dopamine release in the nucleus accumbens shell. Alcohol Alcohol. 2007 Feb 16;42(5):413-6.

39. Batel P, Pessione F, Maitre C, Rueff B. Relationship between alcohol and tobacco dependencies among alcoholics who smoke. Addiction. 1995 Jul;90(7):977-80.

40. Dragone D, Manaresi F, Savorelli L. Obesity and Smoking: Can We Catch Two Birds with One Tax? Health Econ. 2015;25(11):1464-1482.

41. Su S-JB, Yen ST. A censored system of cigarette and alcohol consumption. Appl Econ. 2000 May;32(6):729-37.

42. García-Díaz V, Fernández-Feito A, Arias L, Lana A. Consumo de tabaco y alcohol según la jornada laboral en España. Gac Sanit. 2015 Sep;29(5):364-9.

43. Manrique J, Jensen $\mathrm{H}$. Consumption of tobacco and alcoholic beverages among Spanish consumers. Southwest Econ Rev. 2004;31:41-56.

44. Chang $\mathrm{H}-\mathrm{H}$, Just DR, Lin B-H. Smoking, drinking, and the distribution of adult body weight. Soc Sci J. 2010 Jun;47(2):372-91.

45. Bussu A, Detotto $C$. The bidirectional relationship between gambling and addictive substances. Int Gambl Stud. 2015 May 4;15(2):285-308.

46. Ferreira MM, Torgal MC. Tobacco and Alcohol Consumption among Adolescents. Rev Lat Am Enfermagem. 2010 Apr;18(2):255-61.

47. Börsch-Supan A. Survey of Health, Ageing and Retirement in Europe (SHARE) Wave 4. Release version: 5.0.0. SHARE-ERIC. Data set.; 2013. 
48. Börsch-Supan A. Survey of Health, Ageing and Retirement in Europe (SHARE) Wave 4 [Internet]. SHARE-ERIC. Data set; 2016 [cited 2016 Jun 20]. Available from: http://dx.doi.org/10.6103/SHARE.w4.500

49. Börsch-Supan A, Brandt M, Hunkler C, Kneip T, Korbmacher J, Malter F, et al. Data Resource Profile: The Survey of Health, Ageing and Retirement in Europe (SHARE). Int J Epidemiol. 2013a;42(4):992-1001.

50. Börsch-Supan A, Brandt $M$, Litwin $H$, Weber $G$. Active ageing and solidarity between generations in Europe. First results from SHARE after the economic crisis. Berlin: De Gruyter; 2013b.

51. Malter F, Börsch-Supan (eds.) A. SHARE Wave 4: Innovations \& Methodology. Munich: MEA, Max Planck Institute for Social Law and Social Policy.; 2013.

52. Instituto Nacional de Estatística. Censos 2011 - Resultados definitivos Portugal. Lisboa; 2012.

53. Instituto Nacional de Estatística. Contas económicas regionais [Internet]. 2011 [cited 2016 Sep 15]. Available from: http://www.ine.pt

54. Instituto Nacional de Estatística. População média anual residente (Série longa, início 1971 - 2015). 2016.

55. Cutler DM, Glaeser E. What Explains Differences in Smoking, Drinking, and Other Health-Related Behaviors? Am Econ Rev. 2005 May;95(2):238-42.

56. OECD. Tackling Harmful Alcohol Use [Internet]. Paris: OECD Publishing; 2015 [cited 2015 Dec 30]. Available from: http://www.oecd-ilibrary.org/social-issuesmigration-health/tackling-harmful-alcohol-use_9789264181069-en

57. Cameron C, Trivedi P. Microeconometrics: methods and applications. Cambridge ; New York: Cambridge University Press; 2005. 1034 p.

58. Greene WH. Econometric analysis. 5th ed. Upper Saddle River, N.J: Prentice Hall; 2003. 1026 p.

59. Guiso L, Paiella M. The role of risk aversion in predicting individual behavior. In: Temi di discussione del Servizio Studi. Rome: Banca d'Italia; 2005.

60. Eeckhoudt LR, Hammitt JK. Does risk aversion increase the value of mortality risk? J Environ Econ Manag. 2004 Jan;47(1):13-29.

61. Nayga R, Capps O. Analysis of alcohol consumption in the United States: Probability and level of intake. J Food Distrib Res. 1994;September 94:17-23.

62. Quirmbach D, Gerry CJ. Gender, education and Russia's tobacco epidemic: A lifecourse approach. Soc Sci Med. 2016 Jul;160:54-66.

63. Douglas S. The duration of the smoking habit. Econ Inq. 1998 Jan;36(1):49-64.

64. Kidd MP, Hopkins S. The Hazards of Starting and Quitting Smoking: Some Australian Evidence. Econ Rec. 2004 Jun;80(249):177-92.

65. Malhotra N, Boudarbat B. The Hazards of Starting the Cigarette Smoking Habit. Int J Econ Perspect. 2008;2(4). 
66. Adda J, Lechene V. Health Selection and the Effect of Smoking on Mortality. Scand J Econ. 2013;115(3):902:931.

67. Room R. Smoking and drinking as complementary behaviours. Biomed Pharmacother. 2004 Mar;58(2):111-5.

68. Geiger BB, Mackerron G. Can alcohol make you happy? A subjective wellbeing approach. Soc Sci Med. 2016 May;156:184-91.

69. Bobo J, Husten C. Sociocultural influences on smoking and drinking. Alcohol Res Health. 2000;24(4):225-32. 